\title{
Failure to deflate endotracheal tube cuff due to improper fixation
}

Editor, - It is a routine practice in anaesthesia to deflate the cuff of the endotracheal tube prior to extubation of the trachea. We report an interesting case, where improper fixation of the endotracheal tube resulted in malfunctioning of the tube thereby causing extubation of the trachea with an inflated cuff.

A 35 year old male scheduled for upper limb surgery was intubated with an $8 \mathrm{~mm}$ cuffed endotracheal tube. The surgery was uneventful. At the end of the surgery, the cuff was deflated by aspirating air from the pilot balloon. The adhesive tapes were loosened and endotracheal tube was pulled out of the trachea. However the cuff of the endotracheal tube was found to be inflated. (Figure I) We tried to deflate the endotracheal cuff by aspirating air from the deflated pilot balloon, but the inflation line was not functioning. On closer inspection, it was found that the adhesive tapes were kinking the inflation line and occluding the lumen. The partially attached adhesive tapes were removed, following which the cuff could be easily inflated and deflated. Postoperatively our patient had mild sore throat.

Malfunctioning of the inflation tubing secondary to a bite block or a retained bandage have been reported. ${ }^{1}$

Tracheal extubation without cuff deflation can result in spasm, vocal cord oedema and trauma to the laryngeal structures. ${ }^{2}$ Complications ranging from minor sore throat to life threatening bronchospasm have been reported.

Utmost care should be taken to secure the endotracheal tube properly. Anaesthesia residents, in training should be taught the proper technique of tube fixation. Basic principles of tube fixation of applying traction and counter traction should be followed. We should be cautious, not to impinge the inflation line in the adhesive tapes. Overlapping of the adhesive tapes should be avoided. ${ }^{3}$ A slight carelessness on the part of anaesthesia residents can result in life threatening complications for the patient.

Divya Jain, Indu Bala. Department of Anaesthesiology, PGIMER, Chandigarh, India.

\section{References}

1. Gliech JG, Mauermann WJ, Torres NE. An unusual case of difficult extubation. Respiratory Care. 2008;53:376.

2. Suman S, Ganjoo P, Tandon MS. Difficult extubation due to failure of an endotracheal tube cuff deflation. J Anaesthesiol Clin Pharmacol. 2011; 27(1): 141-2. PMid:21804739 PMCid:3146146

3. Gupta B, Farooque K, Jain D, Kapoor R. Improper tube fixation causing a leaky cuff. J Emerg Trauma Shock. 2010 ; 3(2): 182-4. http://dx.doi.org/10.4103/0974-2700.62125 PMid:20606797 PMCid:2884451

\section{Figure 1}

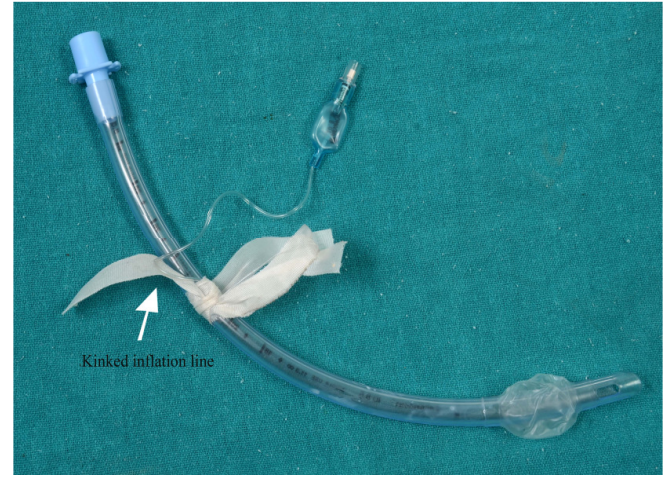

